\title{
GLAD!
}

Revue sur le langage, le genre, les sexualités

$10 \mid 2021$

Varia

\section{Marie Mathieu, Vanina Mozziconacci, Lucile Ruault et Armelle Weil (dir.). 2020. " Partir de soi : expériences et théorisations », Nouvelles questions féministes vol. 39}

Noémie Marignier

\section{(2) OpenEdition}

\section{Journals}

Édition électronique

URL : https://journals.openedition.org/glad/2775

DOI : $10.4000 /$ glad. 2775

ISSN : 2551-0819

Éditeur

Association GSL

Référence électronique

Noémie Marignier, « Marie Mathieu, Vanina Mozziconacci, Lucile Ruault et Armelle Weil (dir.). 2020.

"Partir de soi : expériences et théorisations », Nouvelles questions féministes vol. 39 », GLAD! [En ligne], 10 | 2021, mis en ligne le 15 juillet 2021, consulté le 26 juillet 2021. URL : http:// journals.openedition.org/glad/2775; DOI : https://doi.org/10.4000/glad.2775

Ce document a été généré automatiquement le 26 juillet 2021.

\section{(†) $\odot$

La revue GLAD! est mise à disposition selon les termes de la Licence Creative Commons Attribution Pas d'Utilisation Commerciale - Pas de Modification 4.0 International. 


\title{
Marie Mathieu, Vanina
} Mozziconacci, Lucile Ruault et Armelle Weil (dir.). 2020. «Partir de soi : expériences et théorisations", Nouvelles questions féministes vol. 39

\author{
Noémie Marignier
}

\section{RÉFÉRENCE}

Marie Mathieu, Vanina Mozziconacci, Lucile Ruault et Armelle Weil (dir.). 2020. «Partir de soi : expériences et théorisations ", Nouvelles questions féministes, vol. 39, 2020/1.

1 Le volume 39/1 de Nouvelles questions féministes, coordonné par Marie Mathieu, Vanina Mozziconacci, Lucile Ruault et Armelle Weil, intitulé «Partir de soi : expériences et théorisations ", est consacré à la question de l'expérience et aux épistémologies féministes du point de vue. L'ambition du numéro est plurielle : s'interroger sur ce que les rapports de genre font à la production académique, discuter les apports scientifiques des épistémologies du standpoint, questionner les implications de l'élaboration de savoirs explicitement situés, mais également, dans un mouvement réflexif, interroger la place de l'ignorance dans le monde scientifique. Ce numéro thématique est composé d'une introduction et de quatre articles, provenant principalement de jeunes chercheuses en philosophie ; il est complété par un entretien de deux des coordinatrices avec Michelle Le Doeuff qui revient sur son parcours scientifique, académique et militant.

2 Dans «Une lutte à soi. La politique en première personne des féministes des années 1970 », Léa Védie s'intéresse aux luttes féministes qui mettent au centre l'expérience vécue des femmes, en s'interrogeant sur «la délimitation du sujet politique du 
féminisme» (p. 17) dans les mouvements français et états-uniens des années 1970. Védie montre que ces luttes s'inscrivent dans le rejet d'un certain militantisme à gauche qui disjoint le sujet et l'objet de l'action politique : à rebours, les féministes proposent un militantisme où les femmes luttent pour elles-mêmes, en première personne. La deuxième partie de l'article montre les limites d'une telle approche, notamment telles qu'elles ont été formulées par le féminisme noir ou chicana : le risque est celui d'une "restriction du champ des causes susceptibles d'être appelées féministes» (p. 23) avec la mise au centre des préoccupations des femmes blanches (souvent bourgeoises).

3 «Remédier au paradoxe de l'expérience corporelle au moyen d'une épistémologie du point de contact » d'Anaïs Choulet part du paradoxe suivant : si l'expérience corporelle des femmes est mise au centre du féminisme qui s'intéresse aux questions de santé, cela "présuppose non seulement la capacité à communiquer son vécu, mais surtout la possibilité de disposer d'un tel vécu» (p. 34), ce qui est loin d'être une évidence. Choulet organise sa réflexion autour de la question des "troubles de l'intéroception ", c'est-à-dire : « une défaillance des perceptions internes (faim, désir, émotion, douleur, etc.) et une diminution du vécu de conscience de la maladie» (p. 39) qui touchent principalement les femmes, notamment en raison de l'objectivation sexuelle dont elles sont victimes. Cela lui permet de revisiter Canguilhem et de présenter certaines pratiques du toucher (le shiatsu) comme une voie d'accès à la conscience du corps et à sa mise en discours (éventuellement critique).

4 Margot Giacinti, dans " "Nous sommes le cri de celles qui n'en ont plus" : historiciser et penser le féminicide", revient sur l'apparition et la conceptualisation du terme de féminicide. Si celui-ci existe depuis le XIX ${ }^{e}$ siècle, ce n'est qu'à partir des années 1970 que les féministes s'en emparent pour insister sur le fait qu' « être tuée parce que l'on est une femme est directement en lien avec l'expérience même d'être une femme » (p. 59). C'est cette dernière dimension, cruciale pour les militantes, qui court le danger d'être occultée : il faut bien placer les féminicides dans un continuum d'oppressions et de violences masculines dont les femmes font l'expérience de manière plus ou moins extrême, mais dont la nature sexiste est un point commun. L'expérience du féminicide doit être située sur ce continuum au risque de mener à une dépolitisation.

Dans « Les féminismes du standpoint sont-ils matérialistes ? ", la démarche de Delphine Frasch est de situer les théories du standpoint dans l'échiquier des théories féministes et d'en saisir le projet d'ensemble. Frasch rappelle tout d'abord que les théories du standpoint ne s'opposent pas à une conception matérialiste de l'idéologie: «en analysant collectivement leur expérience du travail reproductif et de l'aliénation, les femmes s'engagent dans l'élaboration d'une critique sociale d'une radicalité inédite.» (p. 71). Elle confronte ensuite les différentes acceptions de la théorie du standpoint, et propose, à partir du féminisme noir, que celle-ci devienne « un appel à une modestie anti-essentialiste, c'est-à-dire en une invitation à ne pas masquer la spécificité de la trajectoire depuis laquelle on parle, et partant, les limites de son point de vue » (p. 78).

Ce numéro vient combler un certain manque dans l'espace francophone. En effet, si certains textes fondateurs de la théorie du standpoint sont traduits (notamment Haraway), si la dimension située des savoirs est souvent mise en valeur dans les travaux en études genres et féministes, c'est assez souvent pour simplement dire que la science n'est pas neutre, et l'on observe rarement une mise au travail de ces approches d'un point de vue théorique ou dans le cœur des analyses. C'est ce que proposent les articles 
de ce numéro autour de la question de l'expérience. Celle-ci est abordée par plusieurs angles d'attaque, ce qui contribue à la richesse du volume: la confrontation de la théorie du standpoint à d'autres théories féministes permet de situer les savoirs situés, la problématisation de l'expérience en dehors de cette théorie permet de montrer comment cette question a pu être pensée et mise au travail à travers différents courants féministes. C'est ce qui fait une des forces des trois premiers articles: ils mettent réellement la question de l'expérience au travail, à partir de terrains et corpus spécifiques, ce qui permet de donner une assise aux analyses et d'échapper à une lecture généralisante ou abstraite. L'article de Frasch, le plus épistémologique, en ce qu'il expose les différentes alliances et courants qui traversent la théorie du standpoint offre quant à lui une mise en perspective très bienvenue. A la lecture du numéro, on ne peut finalement que concorder avec Védie: "au lieu d'une résolution purement intellectuelle, les théorisations du sujet féministe gagnent à s'ancrer dans des enquêtes portant sur les modalités concrètes selon lesquelles les militant-e.s [...] repensent la distinction entre leurs (nos) luttes et celles des autres, et renégocient ainsi les frontières du "soi" »(p. 30).

INDEX

Thèmes : Actualités 